\title{
Temperature Dependence of Electrical Resistance in Ge-Sb-Te Thin Films
}

\author{
Javier Rocca ${ }^{a}$,Jose Luis García ${ }^{a}$, María Andrea Ureña ${ }^{a}$, Marcelo Fontana ${ }^{\star} \mathbb{D}^{\mathbb{B}}$, Bibiana Arcondo $^{a}$ \\ ${ }^{a}$ Universidad de Buenos Aires, Consejo Nacional de Investigaciones Cientificas y Técnicas (CONICET), \\ Laboratorio de Sólidos Amorfos, Instituto de Tecnologías y Ciencias de la Ingeniería (INTECIN), \\ Facultad de Ingeniería, Paseo Colón 850, (C1063ACV) Buenos Aires, Argentina
}

Received: July 20, 2018; Revised: November 05, 2018; Accepted: January 23, 2019

\begin{abstract}
Nowadays, the Ge-Sb-Te system is studied extensively for use in the field of both electrical and optical non-volatile memories. The key of this application is based on the changes in the physical properties (electrical conductivity or refractive index) of these films as a result of structural transformation between amorphous and crystalline states. Both states are highly stable and it is relatively easy to change between them when they are prepared as thin films. In this work, structural and electrical behaviours with the temperature of thin films with compositions $\mathrm{Ge}_{13} \mathrm{Sb}_{5} \mathrm{Te}_{82}, \mathrm{Ge}_{1} \mathrm{Sb}_{2} \mathrm{Te}_{4}, \mathrm{Ge}_{2} \mathrm{Sb}_{2} \mathrm{Te}_{5}$, $\mathrm{Ge}_{1} \mathrm{Sb}_{4} \mathrm{Te}_{7}$ and $\mathrm{Sb}_{70} \mathrm{Te}_{30}$ (atomic fraction) were studied. Films were obtained by pulsed laser deposition (PLD) using a pulsed Nd:YAG laser $(\lambda=355 \mathrm{~nm})$ and they were structurally characterized by X-ray diffraction. Temperature dependence of electrical resistance was studied for these films from room temperature to $520 \mathrm{~K}$ at a heating rate about $3 \mathrm{~K} / \mathrm{min}$. During crystallization, their electrical resistance falls several orders of magnitude in a narrow temperature range. The electrical conduction activation energies of the amorphous and crystalline states and the crystallization temperature were determined. The crystallization products were characterized by X-ray diffraction. The results were compared with those obtained by other authors.
\end{abstract}

Keywords: Amorphous Materials, Non-volatile memories, Crystallization.

\section{Introduction}

Phase-change materials have been used in rewriteable optical data storage for years and now they seem one of the most promising materials for non-volatile electronic memory applications. For non-volatile memories, a pronounced contrast in electrical resistivity is used. This obeys to an also pronounced contrast in structure between amorphous and crystalline states. The amorphous state has a high resistance. Applying a long low-voltage pulse, locally heats the amorphous region and leads to recrystallization. A higher-voltage in a short pulse applied to the crystalline state leads to local melting and formation of an amorphous region on rapid quenching ${ }^{1}$.

The main properties of a good phase-change material are: high-speed phase transition, long thermal stability of amorphous state, large optical change (for rewriteable optical storage) or large resistance change (for non-volatile electronic storage) between the two states, large cycle number of reversible transitions and high chemical stability ${ }^{1}$. Suitable materials for non-volatile memories have been identified in the past years ${ }^{1-6}$, being the Ge-Sb-Te system the most studied.

The glass forming ability of the Ge-Sb-Te system, for rapid solidification from the liquid, is restricted to a small composition range near the binary eutectic $\mathrm{Ge}_{15} \mathrm{Te}_{85}$ (at. fraction) ${ }^{7}$. Ge-Te system has an eutectic point at $T_{\mathrm{e}} \sim 648 \mathrm{~K}$, formed by the co-precipitation of GeTe and

*e-mail: mfontan@fi.uba.ar
Te. In a previous work, we have studied the crystallization kinetics with the addition of $\mathrm{Sb}$ to the eutectic point, and recognized its crystallization products for the chosen alloy at the amorphization zone $\left(\mathrm{Ge}_{13} \mathrm{Sb}_{5} \mathrm{Te}_{82}\right)^{8}$.

The stable ternary diagram of the Ge-Sb-Te system shows three ternary compounds on the GeTe- $\mathrm{Sb}_{2} \mathrm{Te}_{3}$ line, which can be considered as a quasi-binary system 9-10. These three crystalline phases are $\mathrm{Ge}_{2} \mathrm{Sb}_{2} \mathrm{Te}_{5}, \mathrm{GeSb}_{2} \mathrm{Te}_{4}$ and $\mathrm{GeSb}_{4} \mathrm{Te}_{7}$ and they have incongruent melting points at 902 , 889 and $879 \mathrm{~K}$ respectively. The compounds $\mathrm{Ge}_{2} \mathrm{Sb}_{2} \mathrm{Te}_{5}$, $\mathrm{GeSb}_{2} \mathrm{Te}_{4}$ and $\mathrm{GeSb}_{4} \mathrm{Te}_{7}$ have been extensively studied and have the following characteristics: high thermal stability at room temperature, high crystallization rate and very good reversibility between amorphous and crystalline phases.

Amorphous films of the $\mathrm{GeTe}-\mathrm{Sb}_{2} \mathrm{Te}_{3}$ pseudobinary system were obtained by an electron beam co-evaporation method ${ }^{11}$. They were found to have featuring characteristics for optical memory material presenting a large optical change and enabling high-speed one-beam data rewriting. Studies of calorimetric technique and X-rays diffraction show that metastable phases appear when these films are thermally treated. Yamada et al. ${ }^{11}$ reported that $\mathrm{Ge}_{2} \mathrm{Sb}_{2} \mathrm{Te}_{5}, \mathrm{GeSb}_{2} \mathrm{Te}_{4}$ and $\mathrm{GeSb}_{4} \mathrm{Te}_{7}$ compounds present two crystalline states: one is a metastable face centered cubic and the other is a stable structure. The metastable crystalline structure is a rocksaltlike, where Te atoms occupy the $\mathrm{Cl}$ sublattice, while the $\mathrm{Na}$ sublattice is randomly occupied by $\mathrm{Ge} / \mathrm{Sb}$ atoms and intrinsic vacancies. The stable crystalline structures in the 
pseudobinary system are formed by a variety of stable phases with complicated structures. The $\mathrm{Ge}_{2} \mathrm{Sb}_{2} \mathrm{Te}_{5}$ composition (amorphous material - fcc cell transition) exhibits the best performance when used in DVD-RAM in terms of stability and speed ${ }^{12-15}$.

Three zones of the Ge-Sb-Te diagram were identified as suitable materials for rewriteable storage: the first in the vicinity of the $\mathrm{Ge}_{15} \mathrm{Te}_{85}$ eutectic, the second in the region of the pseudo-binary diagram $\mathrm{GeTe}-\mathrm{Sb}_{2} \mathrm{Te}_{3}$ and the third in the vicinity of the $\mathrm{Sb}_{70} \mathrm{Te}_{30}$ composition ${ }^{1}$. In this work, thin films of different compositions which are representative of these three zones were obtained by pulsed laser deposition (PLD). Their structural and electrical behaviours with the temperature were studied and compared with previous works.

\section{Experimental}

Thin films were prepared by pulsed laser deposition (PLD) from chalcogenide targets having the following compositions within the Ge-Sb-Te system: $\mathrm{Ge}_{13} \mathrm{Sb}_{5} \mathrm{Te}_{82}$, $\mathrm{Ge}_{1} \mathrm{Sb}_{2} \mathrm{Te}_{4}, \mathrm{Ge}_{2} \mathrm{Sb}_{2} \mathrm{Te}_{5}, \mathrm{Ge}_{1} \mathrm{Sb}_{4} \mathrm{Te}_{7}$ and $\mathrm{Sb}_{70} \mathrm{Te}_{30}$ (expressed as atomic fraction). Bulk samples with these compositions were first prepared by direct synthesis from pure elements $(4 \mathrm{~N})$ in evacuated silica ampoules ${ }^{16}$. After this process, samples were sliced and polished to obtain PLD targets with parallel faces.

Thin films were deposited on static substrates (chemically cleaned microscope glass slides) held at room temperature, which were parallelly aligned to the target surface, inside a vacuum chamber. PLD was performed using a pulsed $\mathrm{Nd}$ :YAG laser (Spectra-Physics Quanta-Ray Lab-150) with deposition times of 30-40 minutes, operating at a $355 \mathrm{~nm}$ wavelength, with a $5 \mathrm{~ns}$ pulse duration and a $10 \mathrm{~Hz}$ repetition rate. The laser beam with a $45^{\circ}$ angle of incidence was horizontally spanned by moving a mirror in order to get uniform ablation of the target surface. The energy density of the laser spot was $1.1-1.3 \mathrm{~J} / \mathrm{cm}^{2}$.

Film thicknesses, shown in Table 1, were measured by atomic force microscopy (AFM).

Electrical resistance was measured on the surface of the deposited films, using a two-point probe over sputtered Pt-contacts, in coplanar configuration separated by a length $L$, connected to a low-current/high-resistance electrometer. Films were placed in a vacuum cell (evacuated to $10^{-2} \mathrm{mbar}$ with rotary pump) and heated by a resistance furnace with a heating rate of $3 \mathrm{~K} / \mathrm{min}$.

With the aim of studying the crystallization steps, measurements of electrical resistance were performed while heating until several upper limits of temperature for each film composition. As-obtained films and their crystallization steps were analyzed by X-ray diffraction at room temperature in a $\Theta-\Theta$ diffractometer using monochromatized $\mathrm{Cu}\left(\mathrm{K}_{\alpha}\right)$ radiation.

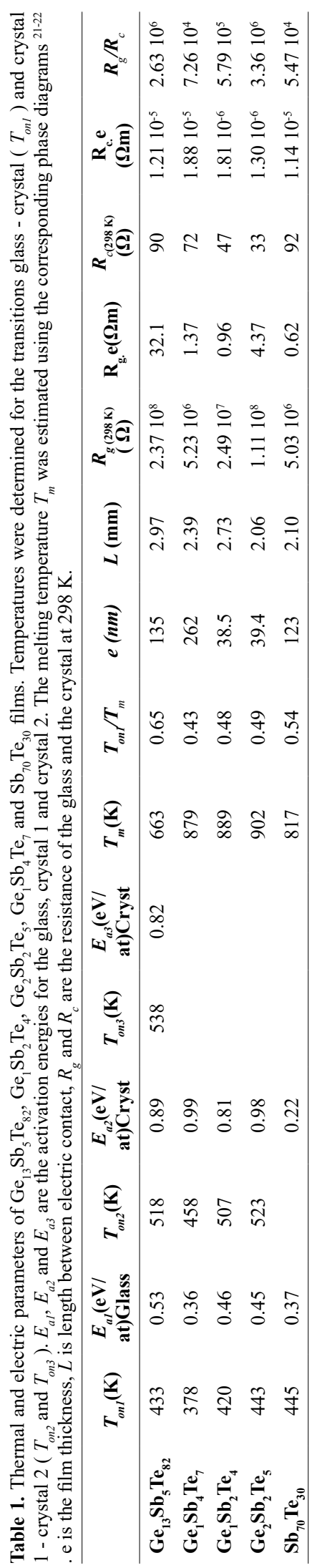




\section{Results and Discussion}

Thin film electrical resistance $R$ of samples with compositions $\mathrm{Ge}_{13} \mathrm{Sb}_{5} \mathrm{Te}_{82}, \mathrm{Ge}_{1} \mathrm{Sb}_{2} \mathrm{Te}_{4}, \mathrm{Ge}_{2} \mathrm{Sb}_{2} \mathrm{Te}_{5}, \mathrm{Ge}_{1} \mathrm{Sb}_{4} \mathrm{Te}_{7}$ and $\mathrm{Sb}_{70} \mathrm{Te}_{30}$ evolve upon heating and successive cooling as shown in Figure 1. Each $R(T)$ plot shows one or more sharp transitions where the value of resistance falls some orders of magnitude in a small temperature range. These transitions are associated with structural changes ${ }^{17}$.

Temperature dependence of electrical resistance $R(T)$ in the $\mathrm{Ge}_{2} \mathrm{Sb}_{2} \mathrm{Te}_{5}$ film has two sharp transitions at about 443 and $523 \mathrm{~K}$. As it is well known in many previous works, the first transformation is associated with a transition between amorphous and crystalline $\mathrm{Ge}_{2} \mathrm{Sb}_{2} \mathrm{Te}_{5}$ (fcc metastable structure) and the second one with a transformation from fcc- $\mathrm{Ge}_{2} \mathrm{Sb}_{2} \mathrm{Te}_{5}$ to hexagonal $\mathrm{Ge}_{2} \mathrm{Sb}_{2} \mathrm{Te}_{5}$ (stable structure) ${ }^{11}$. Amorphous and fcc- $\mathrm{Ge}_{2} \mathrm{Sb}_{2} \mathrm{Te}_{5}$ phases behave as semiconductors because their resistance decreases as temperature increases. On the other hand, stable hexagonal $\mathrm{Ge}_{2} \mathrm{Sb}_{2} \mathrm{Te}_{5}$ phase has metallic behaviour as its resistance decreases during cooling.

Similar behaviours (two sharp transitions) are observed for the $\mathrm{Ge}_{1} \mathrm{Sb}_{2} \mathrm{Te}_{4}$ and $\mathrm{Ge}_{1} \mathrm{Sb}_{4} \mathrm{Te}_{7}$ films. However, only a single transition is observed in the $\mathrm{Sb}_{70} \mathrm{Te}_{30}$ film while the $\mathrm{Ge}_{13} \mathrm{Sb}_{5} \mathrm{Te}_{82}$ film has three transitions.

$R(T)$ in the $\mathrm{Ge}_{13} \mathrm{Sb}_{5} \mathrm{Te}_{82}$ film has its three sharp transitions at about 433, 518 and $538 \mathrm{~K}$. Amorphous phase and crystalline phases appearing in the first two stages show semiconductor behaviour. The crystalline phase appearing in the last step shows a metallic behaviour though, as its resistance increases during heating and decreases when cooling.

$R(T)$ in the $\mathrm{Ge}_{1} \mathrm{Sb}_{2} \mathrm{Te}_{4}$ film has its two sharp transitions at about 420 and $575 \mathrm{~K}$. In the $\mathrm{Ge}_{1} \mathrm{Sb}_{4} \mathrm{Te}_{7}$ film its two sharp transitions are found at about 378 and $458 \mathrm{~K}$. In both cases, amorphous phase and crystalline phases appearing in the first stage show semiconductor behaviour, but the last crystallized phases exhibit metallic behaviour.

$R(T)$ in the $\mathrm{Sb}_{70} \mathrm{Te}_{30}$ film has its only sharp transition at about $445 \mathrm{~K}$. Amorphous phase and crystallized phases show semiconductor behaviour. Then, its resistance increases when cooling.

In all the phases showing a semiconductor behaviour, temperature dependence of resistance can be written as the Arrhenius-type equation in eq (1), where $E_{\mathrm{a}}$ is the apparent activation energy, $\mathrm{k}$ is the Boltzmann's constant and $R_{0}$ is a pre-exponential factor.

$$
R(T)=R_{0} \exp \left(\frac{-E_{a}}{k T}\right)
$$

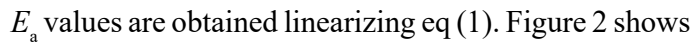
$\ln (R)$ vs $1 / T$ plots for each composition with linear fit where possible, corresponding to semiconductor behaviour of existing phases. Arrhenius plots on temperature dependence of resistance show different regions with the characteristic activation energies for the amorphous and crystalline states.
Thermal and electrical parameters in the glass to crystal transitions for films with compositions $\mathrm{Ge}_{13} \mathrm{Sb}_{5} \mathrm{Te}_{82}, \mathrm{Ge}_{1} \mathrm{Sb}_{2} \mathrm{Te}_{4}$, $\mathrm{Ge}_{2} \mathrm{Sb}_{2} \mathrm{Te}_{5}, \mathrm{Ge}_{1} \mathrm{Sb}_{4} \mathrm{Te}_{7}$ and $\mathrm{Sb}_{70} \mathrm{Te}_{30}$ are shown in Table 1 . Onset temperature $T_{\text {onl }}$ for the glass-crystal transition in $\mathrm{Ge}_{1} \mathrm{Sb}_{2} \mathrm{Te}_{4}, \mathrm{Ge}_{2} \mathrm{Sb}_{2} \mathrm{Te}_{5}, \mathrm{Ge}_{1} \mathrm{Sb}_{4} \mathrm{Te}_{7}$ thin films are in agreement with previous works ${ }^{1,11}$ observing that values are slightly superior in about $15-20 \mathrm{~K}$. $T_{\text {on } 1}$ of $\mathrm{Ge}_{1} \mathrm{Sb}_{2} \mathrm{Te}_{4}, \mathrm{Ge}_{2} \mathrm{Sb}_{2} \mathrm{Te}_{5}$, $\mathrm{Ge}_{1} \mathrm{Sb}_{4} \mathrm{Te}_{7}$ thin films increases with the Ge content in agreement with the bibliography ${ }^{11}$. The value of ratio $R_{\mathrm{g}} / R_{\mathrm{c}}$ (ratio of amorphous state to crystalline state resistances) for the $\mathrm{Ge}_{2} \mathrm{Sb}_{2} \mathrm{Te}_{5}$ alloy is almost an order of magnitude higher than previous results ${ }^{3}$.

Electrical resistance at room temperature of thin films exhibits a remarkable contrast $(\sim \mathrm{M} \Omega-\sim \Omega)$ when measured before and after the thermal treatments due to glass - crystal transition; as we mentioned, this result is an excellent property for phase-change materials. The electrical resistance at room temperature of the amorphous and crystalline phases is shown in Table 1. The changes in the resistance observed in our samples for the amorphous phase are in good accordance with previously known electrical properties of amorphous semiconductors.

X-ray diffractograms of as-deposited films and their crystallization steps at different temperatures are shown in Fig 3. In Figure 1, each red star shows the maximum temperature reached by a sample before an X-ray diffraction experiment was held at room temperature.

X-ray diffractograms of the $\mathrm{Ge}_{13} \mathrm{Sb}_{5} \mathrm{Te}_{82}$ film are shown in Fig 3 (a). X-ray patterns of the PLD as-obtained film are characteristic of a mainly amorphous phase with traces of a crystalline phase. Crystal peaks of small intensity can be associated with either the fcc- $\mathrm{Ge}_{1} \mathrm{Sb}_{2} \mathrm{Te}_{4}$ metastable phase or the fcc- $\mathrm{Ge}_{2} \mathrm{Sb}_{2} \mathrm{Te}_{5}$ metastable phase ${ }^{17}$, as both phases are similar. When that film is heated up to $T=533 \mathrm{~K}$ (after the second transition), X-ray patterns show the appearance of two crystal peaks at $2 \Theta=25.5^{\circ}$ and $28.7^{\circ}$ associated with the hcp- $\mathrm{Ge}_{2} \mathrm{Sb}_{2} \mathrm{Te}_{5}$ stable phase ${ }^{17}$ although it can also be associated with the hcp- $\mathrm{Ge}_{1} \mathrm{Sb}_{2} \mathrm{Te}_{4}$ stable phase ${ }^{15}$. When it is heated up to $T=593 \mathrm{~K}$ (after the third transition), $\mathrm{X}$-ray patterns show the appearance of two crystal peaks at $2 \Theta=12.9^{\circ}$ and $19.4^{\circ}$ associated with the hcp-Ge $\mathrm{Sb}_{2} \mathrm{Te}_{4}$ stable phase ${ }^{15}$. It is worth mentioning that the hcp-Te crystalline stable phase is not detected in this film, despite the fact that the hcp-Te phase is observed in as-cast sample and in the crystallization of amorphous samples obtained by rapid cooling from the liquid ${ }^{8}$. The main peaks of hcpTe phase associated with relative intensity of $16,100,36$ and 25 located in the angles $2 \Theta=23.06^{\circ}, 27.58^{\circ}, 38.29^{\circ}$ and $40.48^{\circ}$ respectively (JCPDS 36-1452) are not observed in the experimental X-ray patterns shown in Figure 3 (a).

$\mathrm{X}$-ray diffractograms of the $\mathrm{Ge}_{1} \mathrm{Sb}_{2} \mathrm{Te}_{4}$ film are shown in Fig 3 (b). X-ray patterns of the PLD as-obtained film are characteristic of a mainly amorphous phase with traces of the fcc- $\mathrm{Ge}_{1} \mathrm{Sb}_{2} \mathrm{Te}_{4}$ metastable crystalline phase ${ }^{15}$. When that film is 


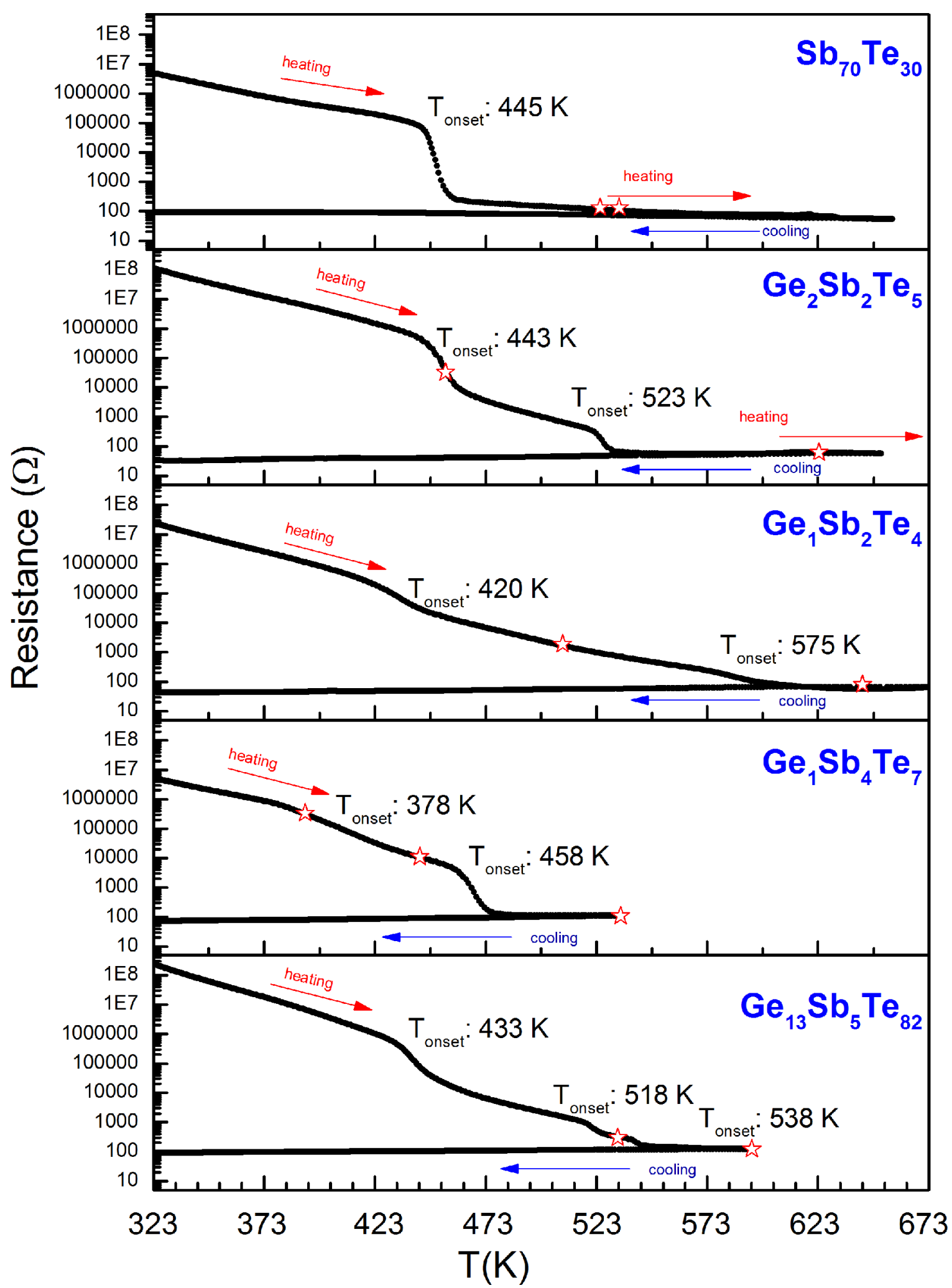

Figure 1. Temperature dependence of electrical resistance for the $\mathrm{Ge}_{13} \mathrm{Sb}_{5} \mathrm{Te}_{82}, \mathrm{Ge}_{1} \mathrm{Sb}_{2} \mathrm{Te}_{4}, \mathrm{Ge}_{2} \mathrm{Sb}_{2} \mathrm{Te}_{5}, \mathrm{Ge}_{1} \mathrm{Sb}_{4} \mathrm{Te}_{7}$ and $\mathrm{Sb}_{70} \mathrm{Te}_{30}$ thin films. Each red star shows the maximum temperature reached by a sample before an $\mathrm{X}$-ray diffraction experiment was held at room temperature. 


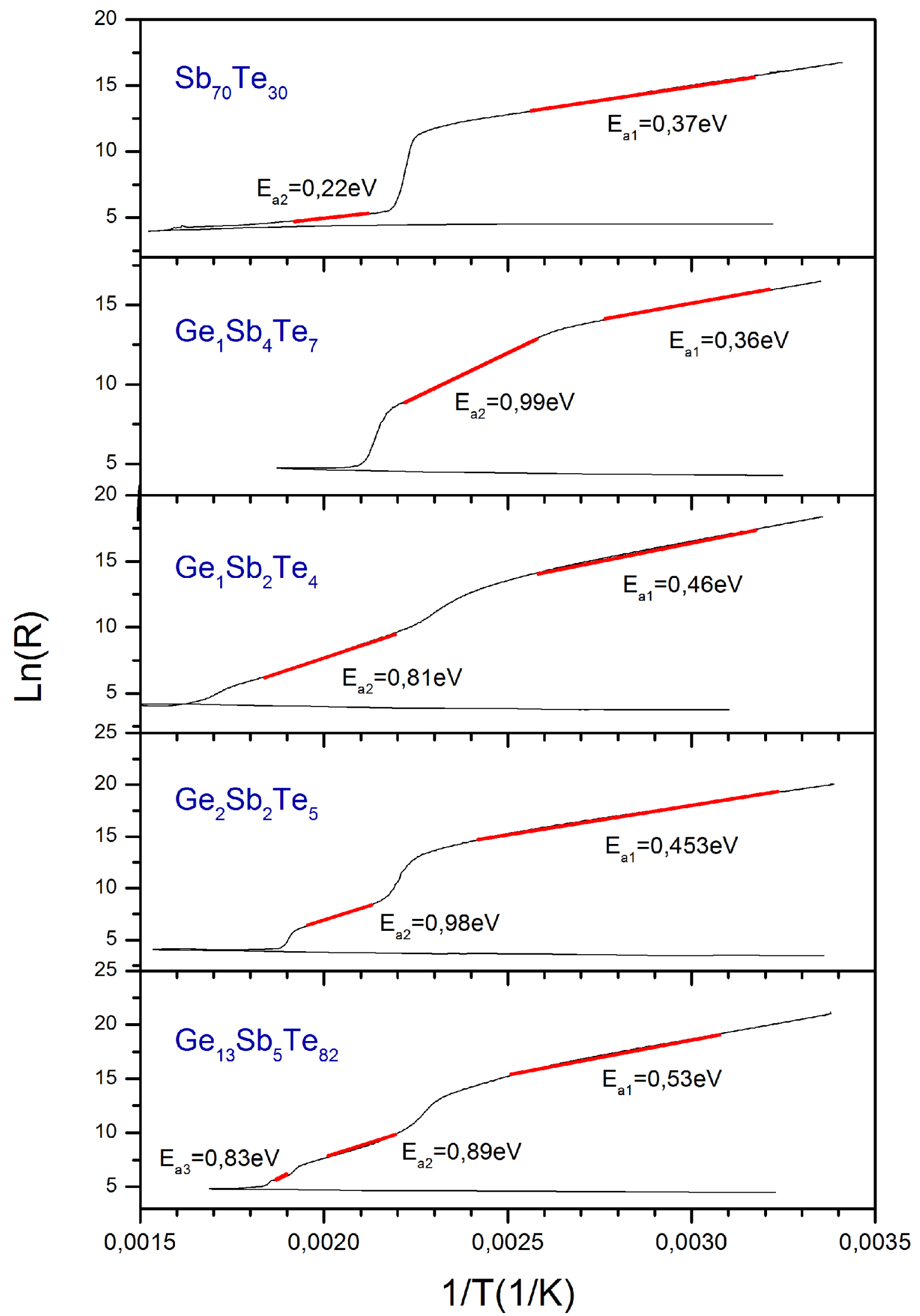

Figure 2. Electrical resistance vs. $1 / T$ for thin films of compositions $\mathrm{Ge}_{13} \mathrm{Sb}_{5} \mathrm{Te}_{82}, \mathrm{Ge}_{1} \mathrm{Sb}_{2} \mathrm{Te}_{4}, \mathrm{Ge}_{2} \mathrm{Sb}_{2} \mathrm{Te}_{5}, \mathrm{Ge}_{1} \mathrm{Sb}_{4} \mathrm{Te}_{7}$ and $\mathrm{Sb}_{70} \mathrm{Te}_{30}$. 

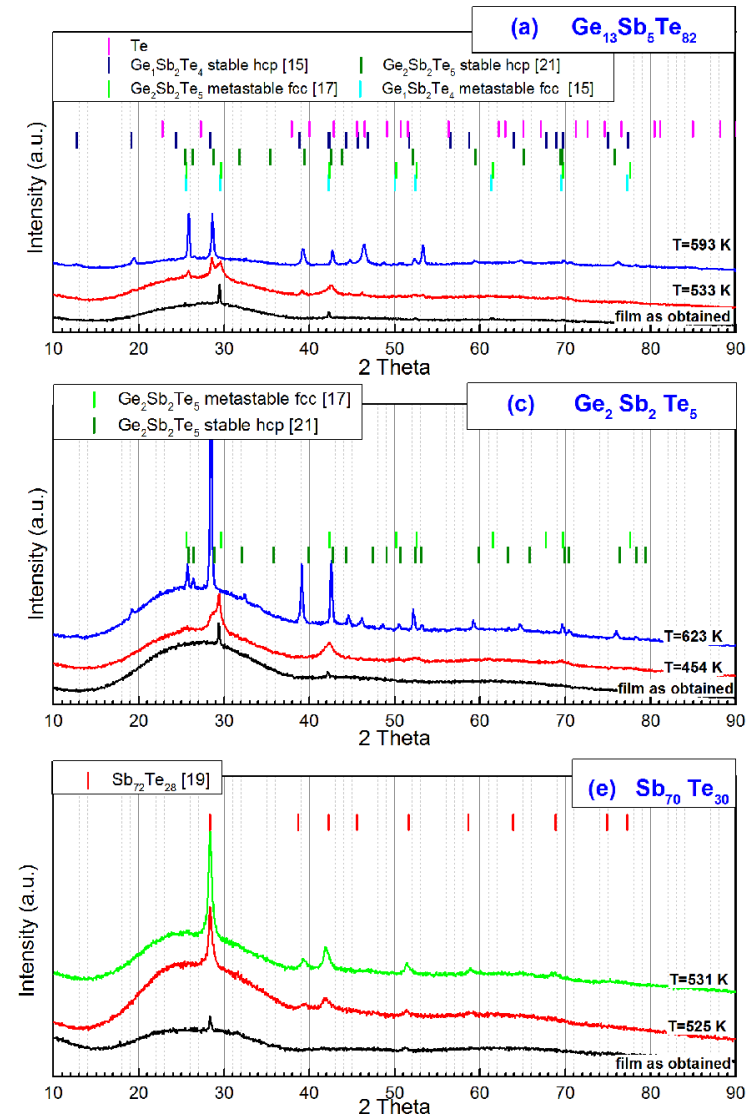

Figure 3. X-ray diffractograms of as-obtained films and their crystallization steps for the compositions (a) $\mathrm{Ge}_{13} \mathrm{Sb}_{5} \mathrm{Te}_{82}$, (b) $\mathrm{Ge}_{1} \mathrm{Sb}_{2} \mathrm{Te}_{4}$, (c) $\mathrm{Ge}_{2} \mathrm{Sb}_{2} \mathrm{Te}_{5}$, (d) $\mathrm{Ge}_{1} \mathrm{Sb}_{4} \mathrm{Te}_{7}$ and (e) $\mathrm{Sb}_{70} \mathrm{Te}_{30}$.

heated up to $T=507 \mathrm{~K}$ (after the first transition, $T_{\text {onl }}=420 \mathrm{~K}$ ), $\mathrm{X}$-ray patterns show the appearance of the hcp- $\mathrm{Ge}_{1} \mathrm{Sb}_{2} \mathrm{Te}_{4}$ stable phase ${ }^{15}$. When it is heated up to $T=644 \mathrm{~K}$, X-ray patterns do not show significant structural changes: only the hcp- $\mathrm{Ge}_{1} \mathrm{Sb}_{2} \mathrm{Te}_{4}$ phase is observed.

$\mathrm{X}$-ray diffractograms of the $\mathrm{Ge}_{2} \mathrm{Sb}_{2} \mathrm{Te}_{5}$ film are shown in Fig 3 (c). X-ray patterns of the PLD as-obtained film are characteristic of a mainly amorphous phase with traces of the fcc- $\mathrm{Ge}_{2} \mathrm{Sb}_{2} \mathrm{Te}_{5}$ metastable crystalline phase ${ }^{17}$. When that film is heated up to $T=454 \mathrm{~K}$ (after the first transition, $T_{\text {on } 1}=443 \mathrm{~K}$ ), X-ray patterns show growing of the fcc$\mathrm{Ge}_{2} \mathrm{Sb}_{2} \mathrm{Te}_{5}$ phase ${ }^{15,20}$ and incipient appearance of the hcp$\mathrm{Ge}_{2} \mathrm{Sb}_{2} \mathrm{Te}_{5}$ stable phase with a peak at $2 \Theta=28.65^{\circ}$. When it is heated up to $T=623 \mathrm{~K}$ (after the second transition, $T_{\text {on2 }}=523 \mathrm{~K}$ ), X-ray patterns only show one crystalline phase: stable hcp- $\mathrm{Ge}_{2} \mathrm{Sb}_{2} \mathrm{Te}_{5}$.

$\mathrm{X}$-ray diffractograms of the $\mathrm{Ge}_{1} \mathrm{Sb}_{4} \mathrm{Te}_{7}$ film are shown in Fig 3 (d). X-ray patterns of the PLD as-obtained film are characteristic of a mainly amorphous phase with traces of a phase similar to metastable fcc- $\mathrm{Ge}_{2} \mathrm{Sb}_{2} \mathrm{Te}_{5}{ }^{17}$. Despite metastable phases have not been found in previous structural works for the composition $\mathrm{Ge}_{1} \mathrm{Sb}_{4} \mathrm{Te}_{7}$, Yamada et al reported ${ }^{17}$ that the first transformation corresponds to a metastable phase. When that film is heated up to $T=392 \mathrm{~K}$ (slightly higher
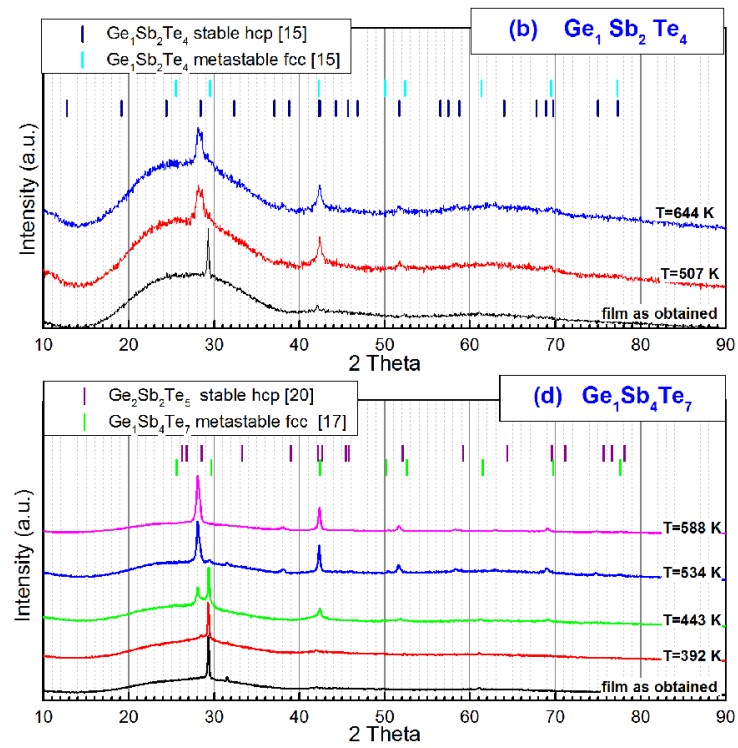

temperature to the first transition, $T_{\text {onl }}=378 \mathrm{~K}$ ) X-ray patterns do not show significant structural changes. When it is heated up to $T=443 \mathrm{~K}$, X-ray patterns show incipient crystallization of the hcp- $\mathrm{Ge}_{1} \mathrm{Sb}_{4} \mathrm{Te}_{7}$ stable phase ${ }^{19}$ in coexistence with the metastable phase. X-ray patterns only show one crystalline phase when the film reaches either $T=534 \mathrm{~K}$ or $T=588 \mathrm{~K}$ (both after the second transition, $T_{\text {on } 2}=458 \mathrm{~K}$ ): the stable hcp- $\mathrm{Ge}_{1} \mathrm{Sb}_{4} \mathrm{Te}_{7}$.

X-ray diffractograms of the $\mathrm{Sb}_{70} \mathrm{Te}_{30}$ film are shown in Fig 3 (e). X-ray patterns of the PLD as-obtained film are characteristic of a mainly amorphous phase with traces of the $\mathrm{Sb}_{72} \mathrm{Te}_{28}$ crystalline phase ${ }^{18}$. X-ray patterns only show the $\mathrm{Sb}_{72} \mathrm{Te}_{28}$ crystalline phase when the film reaches either $T=525 \mathrm{~K}$ or $T=531 \mathrm{~K}$ (both above observed transition) ${ }^{18}$.

\section{Conclusions}

The activation energies reported in Table 1 for conduction in the amorphous state are the expected values for the chalcogenide amorphous materials ${ }^{23}$, observing that the higher values (close to $0.5 \mathrm{eV}$ ) are given for the films of compositions $\mathrm{Ge}_{1} \mathrm{Sb}_{2} \mathrm{Te}_{4}, \mathrm{Ge}_{2} \mathrm{Sb}_{2} \mathrm{Te}_{5}$ and $\mathrm{Ge}_{1} \mathrm{Sb}_{4} \mathrm{Te}_{7}$. A higher value of activation energy implies a greater variation of the electrical resistance in the amorphous state, that is, a greater 
decrease in the resistance with temperature. It is also noted that the activation energy for conduction in the crystalline phase is significantly increased except in the $\mathrm{Sb}_{70} \mathrm{Te}_{30}$ alloy, where it decreases.

The electrical measurements were made in the configuration of two points on the same side of the film. Taking into account the experimental form that was used, the product of the electrical resistance $R$ multiplied by the thickness $e$ of the film gives an order of magnitude of the electrical resistivity of each state. Table 1 reports the values of the product R.e for the amorphous and crystalline states, observing values between 0.6 and $32 \Omega \mathrm{m}$ for the amorphous state and of the order $10^{-5}-10^{-6} \Omega \mathrm{m}$ for the crystalline state.

In view of its application for non-volatile memories, it is interesting to analyze the dimensionless quotients of the crystallization and melting temperatures $T_{\text {onl }} / T_{\mathrm{m}}$, which determines the operating temperature range of the cell, as well as the ratio $R_{\mathrm{g}} / R_{\mathrm{c}}$ (ratio of amorphous state to crystalline state resistances) at $298 \mathrm{~K}$, which determines the resolution range in the electrical resistance between these states. It is desirable that these dimensionless parameters were the largest possible. In the first, it is intended with a larger value, to achieve greater thermal stability of the amorphous phase, while in the second it is desired to have the greatest range of values of resistance that allows to differentiate both states. Taking this into account, it is observed in Table 1, that the $\mathrm{Ge}_{13} \mathrm{Sb}_{5} \mathrm{Te}_{82}$ alloy has the highest $T_{\text {onl }} / T_{\mathrm{m}}$, followed by the $\mathrm{Sb}_{70} \mathrm{Te}_{30}$ alloy. These two alloys also have the lowest activation energy for electrical conduction in the amorphous state. With respect to the dimensionless resistance parameter $R_{\mathrm{g}} / R_{\mathrm{c}}$, the alloys that present the best results are those of compositions $\mathrm{Ge}_{13} \mathrm{Sb}_{5} \mathrm{Te}_{82}$ and $\mathrm{Ge}_{2} \mathrm{Sb}_{2} \mathrm{Te}_{5}$ with values about $3 \cdot 10^{6}$.

\section{Acknowledgements}

The authors acknowledge to Peruilh scholarship (Facultad de Ingeniería-UBA), Universidad de Buenos Aires and CONICET for the financial support.

\section{References}

1. Wuttig M, Yamada N. Phase-change materials for rewriteable data storage. Nature Materials. 2007;6:824-832.

2. Seo JH, Song KH, Lee HY. Crystallization behavior of amorphous $\mathrm{Alx}(\mathrm{Ge} 2 \mathrm{Sb} 2 \mathrm{Te} 5) 1-\mathrm{x}$ thin films. Journal of Applied Physics. 2010;108(6):064515.

3. Cheng HY, Kao KF, Lee CM, Chin TS. Characteristics of Ga-Sb-Te Films for Phase-Change Memory. IEEE Transactions on Magnetics. 2007;43(2):927-929.

4. Wei SJ, Zhu HF, Chen K, Xu D, Li J, Gan FX, et al. Phase change behavior in titanium-doped $\mathrm{Ge}_{2} \mathrm{Sb}_{2} \mathrm{Te}_{5}$ films. Applied Physics Letters. 2011;98(23):231910.

5. Wang M, Lu Y, Shen X, Wang G, Li J, Dai S, et al. Effect of $\mathrm{Sb}_{2} \mathrm{Se}$ on phase change characteristics of $\mathrm{Ge}_{2} \mathrm{Sb}_{2} \mathrm{Te}_{5}$. CrystEngComm. 2015;17(26):4871-4876.
6. Wang G, Nie Q, Shen X, Wang RP, Wu L, Fu J, et al. Phase change behaviors of $\mathrm{Zn}$-doped $\mathrm{Ge}_{2} \mathrm{Sb}_{2} \mathrm{Te}_{5}$ films. Applied Physics Letters. 2012;101(5):051906.

7. Lebaudy P, Saiter JM, Grenet J, Belhadji M, Vautier C. Identification of amorphous zones in the GeTeSb system. Materials Science and Engineering: A. 1991;132:273-276.

8. Rocca J, Erazú M, Fontana M, Arcondo B. Crystallization process on amorphous GeTeSb samples near to eutectic point $\mathrm{Ge}_{15} \mathrm{Te}_{85}$. Journal of Non-Crystalline Solids. 2009;355(37-42):2068-2073.

9. Abrikosov NK, Danilova Dobryakova GT. Izv Akad Nauk SSSR Neorg Mater. 1965;1:204.

10. Legendre B, Hancheng C, Bordas S, Clavaguera-Mora MT. Phase diagram of the ternary system Ge-Sb-Te. I. The subternary GeTe$\mathrm{Sb}_{2} \mathrm{Te}_{3}-\mathrm{Te}$. Thermochimica Acta. 1984;78(1-3):141-157.

11. Yamada N, Ohno E, Nishiuchi K, Akahira N, Takao M. Rapid-phase transitions of $\mathrm{GeTe}-\mathrm{Sb}_{2} \mathrm{Te}_{3}$ pseudobinary amorphous thin films for an optical disk memory. Journal of Applied Physics. 1991;69(5):28492856.

12. Lankhorst MHR, Ketelaars BWSMM, Wolters RAM. Low-cost and nanoscale non-volatile memory concept for future silicon chips. Nature Materials. 2005;4:347-352.

13. Wuttig M, Lüsebrink D, Wamwangi D, Welnic W, Gilleßen M, Dronskowski R. The role of vacancies and local distortions in the design of new phase-change materials. Nature Materials. 2007;6:122128.

14. Park GS, Kwon JH, Kim M, Yoon RH, Jo W, Kim TK, et al. Crystalline and amorphous structures of $\mathrm{Ge}-\mathrm{Sb}-\mathrm{Te}$ nanoparticles. Journal of Applied Physics. 2007;102(1):013524. DOI: https://doi. org/10.1063/1.2752550

15. Matsunaga T, Yamada N, Kubota Y. Structures of stable and metastable Ge2Sb2Te5, an intermetallic compound in GeTe-Sb $\mathrm{Te}_{3}$ pseudobinary systems. Acta Crystallographica B. 2004;60(Pt 6):685-691.

16. Ureña MA, Fontana M, Arcondo B, Clavaguera-Mora MT. Crystallization processes of Ag-Ge-Se superionic glasses. Journal of Non Crystalline Solids. 2003;320(1-3):151-167.

17. Yamada N, Matsunaga T. Structure of laser-crystallized $\mathrm{Ge}_{2} \mathrm{Sb}_{2+\mathrm{x}} \mathrm{Te}_{5}$ sputtered thin films for use in optical memory. Journal of Applied Physics. 2000;88(12):7020-7028.

18. Kifune K, Kubota Y, Matsunaga T, Yamada N. Extremely long periodstacking structure in the Sb-Te binary system. Acta Crystallographica B. 2005;61(Pt 5):492-497.

19. Matsunaga T, Kojima R, Yamada N, Kifune K, Kubota Y, Takata M. Structural Features of $\mathrm{Ge}_{1} \mathrm{Sb}_{4} \mathrm{Te}_{7}$, an Intermetallic Compound in the GeTe- $\mathrm{Sb}_{2} \mathrm{Te}_{3}$ Homologous Series. Chemistry of Materials. 2008;20(18):5750-5755.

20. Urban P, Schneider MN, Erra L, Welzmiller S, Fahrnbauer F, Oeckler $\mathrm{O}$. Temperature dependent resonant X-ray diffraction of singlecrystalline $\mathrm{Ge}_{2} \mathrm{Sb}_{2} \mathrm{Te}_{5}$. CrystEngComm. 2013;15(24):4823-4829.

21. Massalski TB, Okamoto H, Subramanian PR, Kacprzak L, eds. Binary Alloy Phase Diagrams. 2nd ed. Materials Park: ASM International; 1990.

22. Villars P, Prince A, Okamoto H, eds. Handbook of Ternary Alloy Phase Diagrams. Materials Park: ASM International; 1995.

23. Mott NF, Davis EA, eds. Electronic Processes in Non-Crystalline Materials. Oxford: Clarendon Press; 1971. 